The Identification of Economic Benefits for Local Communities in the Implementation of Sustainable Tourism in Kereng Bangkirai Tourism Village

\author{
Yustisia Kristiana1, Theodosia C. Nathalia²
}

\author{
1,2, Universitas Pelita Harapan \\ Correspondence : Yustisia Kristina, Universitas Pelita Harapan \\ Email : yustisia.kristina@uph.edu \\ DOI : https://doi.org/10.36983/japm.v9i2.175
}

\begin{abstract}
Kereng Bangkirai Tourism Village strives to be a tourist destination that applies the concept of sustainable tourism. Tourism development in Kereng Bangkirai Tourism Village has provided economic benefits, therefore it is hoped that the economic benefits for the community can be felt in a sustainable manner. A larger market segment will provide economic benefits but if not managed properly it will cause losses for local communities. The purpose of this study is to identify economic benefits for local communities based on the criteria for implementing sustainable tourism destinations in Kereng Bangkirai Tourism Village. This research uses a qualitative approach. Data collection techniques in this study using in-depth interviews and observation techniques. Informants are managers of tourism villages, community communities, associations, industry and the Department of Culture and Tourism of Palangka Raya City. This research uses descriptive analysis. The results show that the tourism sector has provided economic benefits and simultaneously applies the principles of sustainable tourism.
\end{abstract}

Keywords: tourism village, economic benefits, sustainable tourism

\title{
Identifikasi Manfaat Ekonomi untuk Masyarakat Lokal dalam Penerapan Pariwisata Berkelanjutan di Desa Wisata Kereng Bangkirai
}

\begin{abstract}
ABSTRAK
Desa Wisata Kereng Bangkirai berupaya untuk menjadi destinasi wisata yang menerapkan konsep pariwisata berkelanjutan. Pengembangan pariwisata di Desa Wisata Kereng Bangkirai telah memberi manfaat ekonomi, oleh sebab itu diharapkan manfaat ekonomi bagi masyarakat dapat dirasakan secara berkelanjutan. Segmen pasar yang lebih besar akan memberikan keuntungan ekonomi namun bila dikelola dengan kurang baik maka akan memberikan dampak negatif bagi masyarakat lokal. Tujuan dari penelitian ini adalah untuk mengidentifikasi manfaat ekonomi bagi masyarakat lokal berdasarkan kriteria dalam penerapan destinasi pariwisata berkelanjutan di Desa Wisata Kereng Bangkirai. Penelitian ini menggunakan pendekatan kualitatif. Teknik pengumpulan data dalam penelitian ini menggunakan teknik wawancara mendalam dan observasi. Informan adalah pengelola desa wisata, komunitas masyarakat,
\end{abstract}


asosiasi, industri dan Dinas Kebudayaan dan Pariwisata Kota Palangka Raya. Penelitian ini menggunakan analisa deskriptif. Hasil penelitian menunjukkan bahwa sektor pariwisata telah memberi manfaat ekonomi dan secara beriringan menerapkan prinsip pariwisata berkelanjutan.

\section{Kata kunci: desa wisata, manfaat ekonomi, pariwisata berkelanjutan}

\section{PENDAHULUAN}

Pulau Kalimantan dikenal sebagai pulau terbesar ketiga di dunia, dengan keragaman sumber daya alam sebagai daya tarik wisata. Salah satu provinsi di Kalimantan yang mengembangkan pariwisata adalah Provinsi Kalimantan Tengah. Rencana Pembangunan Jangka Menengah Daerah (RPJMD) Provinsi Kalimantan Tengah Tahun 2016-2021 menempatkan pariwisata sebagai sektor prioritas dalam meningkatkan kesejahteraan masyarakat Kalimantan Tengah. Meningkatnya sektor pariwisata telah mendorong pertumbuhan ekonomi daerah Provinsi Kalimantan Tengah tahun 2018 hingga mencapai 7,6 persen atau melampaui pertumbuhan ekonomi nasional yang hanya 5,6 persen.

Kelurahan Kereng Bangkirai merupakan salah satu kelurahan di Kecamatan Sebangau, Kota Palangka Raya, Kalimantan Tengah dengan luas wilayah seluas 20.050 hektar, adapun jumlah penduduk sebesar 7.530 jiwa, dan dengan bentang alam geografis yaitu hutan tropis yang masih alami, tanah rawa gambut dan dilintasi Sungai Sebangau. Lokasi Kelurahan Kereng Bangkirai sekitar 11 km dan apabila dari Bandar Udara Tjilik Riwut hanya sekitar $12 \mathrm{~km}$.

Kereng Bangkirai merupakan pintu masuk utama menuju kawasan Taman Nasional Sebangau. Taman Nasional Sebangau merupakan kawasan pelestarian hutan rawa gambut terbesar di Indonesia dengan luas sekitar 568.700 hektar. Taman Nasional Sebangau merupakan rumah bagi lebih dari 6.000 orangutan sehingga menjadikan tempat ini salah satu populasi orangutan terbesar di alam liar. Hutan di Taman Nasional Sebangau dikenal dengan ekosistem khusus air hitam. Ekosistem air hitam berasal dari bahan-bahan organik yang membusuk di rawa gambut sehingga air menjadi hitam. Dalam ekosistem ini terdapat beragam organisme unik yang hidup.

Melihat potensi wisata yang dimiliki dan untuk lebih mempercepat pembangunan wisata di kawasan wisata Kereng Bangkirai maka Pemerintah Kota Palangka Raya melalui Dinas Kebudayaan dan Pariwisata Kota Palangka Raya menerbitkan Keputusan Walikota Palangka Raya No. 188.45/257/2016 tentang Pembentukan Tim Percepatan Pembangunan Kereng Bangkirai. Selanjutnya diterbitkan Keputusan Walikota Palangka Raya No. 188.45/211/2018 tentang Penetapan Kelurahan Kereng Bangkirai Sebagai Salah Satu Desa Wisata di Kota Palangka Raya. Upaya yang dilakukan ini merupakan keseriusan dan wujud nyata Pemerintah Kota Palangka Raya agar Desa Wisata Kereng Bangkirai dapat tumbuh dan berkembang secara berkelanjutan sebagai salah satu produk wisata unggulan di Kota Palangka Raya.

Jumlah kunjungan wisatawan ke

Desa Wisata Kereng Bangkirai terus meningkat, tercatat jumlah kunjungan pada tahun 2016 sejumlah 18.875 wisatawan, 
2017 berjumlah 27.200 wisatawan dan tahun 2018 berjumlah 38.113 wisatawan atau setiap tahunnya rerata pertumbuhan wisatawan meningkat sebesar 42,11\%. Kegiatan pariwisata mampu memberikan manfaat ekonomi bagi masyarakat. Hal ini sejalan dengan penetapan kawasan wisata Kereng Bangkirai oleh Pemerintah Kota Palangka Raya ke dalam zona 1 pengembangan industri pariwisata. Zona 1 ini oleh Pemerintah Kota Palangka Raya akan ditata menjadi daya tarik wisata dan dikembangkan ekonomi lokal.

Desa Wisata Kereng Bangkirai berupaya untuk menjadi destinasi wisata yang menerapkan konsep pariwisata berkelanjutan. Pengembangan pariwisata di kawasan ini telah memberi manfaat ekonomi, oleh sebab itu diharapkan manfaat ekonomi bagi masyarakat dapat dirasakan secara berkelanjutan. Hariman (2021) menyatakan bahwa pengembangan desa wisata berdampak pada kesejahteraan ekonomi masyarakat. Kartika (2017) menambahkan bahwa dampak positif dari aspek ekonomi yaitu mampu mendorong peningkatan Pendapatan Asli Desa (PAD), pendapatan masyarakat karena ketersediaan peluang pekerjaan, serta meningkatkan pembangunan desa.

Desa Wisata Kereng Bangkirai sebagai daya tarik yang berada dalam tahap pembangunan akan senantiasa meningkatkan kualitas dan daya saing produk dalam menarik minat dan loyalitas segmen pasar yang ada. Segmen pasar yang lebih besar akan memberikan keuntungan ekonomi namun bila dikelola dengan kurang baik maka akan memberikan dampak negatif bagi masyarakat lokal.

Berdasarkan uraian tersebut, tujuan dari penelitian yang dilakukan di Desa Wisata Kereng Bangkirai adalah untuk mengidentifikasi manfaat ekonomi bagi masyarakat lokal berdasarkan kriteria dalam penerapan destinasi pariwisata berkelanjutan di Desa Wisata Kereng Bangkirai.

\section{KERANGKA KONSEP}

\section{Desa Wisata}

Desa wisata berada di wilayah administratif desa dengan potensi keunikan daya tarik wisata yang khas yaitu merasakan pengalaman keunikan kehidupan dan tradisi kehidupan masyarakat di pedesaan dengan segala potensinya (Kementerian Pariwisata Republik Indonesia, 2019). Desa wisata adalah tempat dimana sekelompok kecil wisatawan tinggal di dalam kawasan atau di area sekitarnya dengan suasana tradisional, seringkali secara lokasi tergolong terpencil, dan wisatawan belajar tentang kehidupan (Inskeep, 1991).

Pengembangan desa wisata dinilai mampu meminimalkan potensi urbanisasi masyarakat dari pedesaan ke perkotaan karena mampu menciptakan kegiatan ekonomi di pedesaan yang berbasis pada kegiatan pariwisata atau disebut ekonomi pariwisata. Perkembangan desa wisata yang pesat perlu didukung dengan penyusunan pedoman pembinaan desa wisata yang selanjutnya dapat dijadikan acuan bagi semua pemangku kepentingan dalam pengembangan desa wisata yang dapat memberikan manfaat bagi masyarakat lokal melalui pengembangan pariwisata berkelanjutan melalui pariwisata berbasis masyarakat lokal. Pedoman ini diharapkan dapat mendorong pengembangan pariwisata berkelanjutan dan pengelolaan desa wisata yang lebih fokus, dan terencana (Hamzah \& Irfan, 2018).

\section{Pemanfaatan Ekonomi Dalam Konsep Pariwisata Berkelanjutan}


Dampak ekonomi dari pariwisata dapat dikelompokkan menjadi dampak berwujud disebut juga kuantitatif atau langsung dikuantifikasi dalam nilai moneter, dan tidak berwujud disebut kualitatif atau tidak langsung terukur (Metzel, 2007; Woltering, 2012). Dampak positif baik berwujud maupun tidak berwujud sesuai dengan manfaat pariwisata bagi masyarakat dan ekonomi. Dwyer, Forsyth, dan Dwyer (2010) menunjukkan bahwa manfaat ekonomi dari pariwisata tidak sama dengan dampak ekonomi dari pariwisata maupun kontribusi ekonomi dari pariwisata. Pengertian manfaat ekonomi dari pariwisata mensyaratkan bahwa warga negara harus lebih diuntungkan dengan adanya pariwisata dibandidngkan tanpa adanya pariwisata. Dengan demikian, keuntungan bersih yang harus dianalisis, yang mencakup baik pertimbangan biaya pengembangan pariwisata maupun biaya peluang kegiatan pariwisata.

Peraturan Menteri Pariwisata No. 14 Tahun 2016 tentang Pedoman Destinasi Pariwisata Berkelanjutan menyatakan pariwisata berkelanjutan adalah pariwisata yang memperhatikan pengaruh terhadap aspek ekonomi, sosial budaya, dan lingkungan pada kondisi sekarang dan masa yang akan datang, memenuhi kebutuhan wisatawan, industri, lingkungan, dan masyarakat serta dapat dilaksanakan pada semua aktivitas wisata di seluruh tipe destinasi pariwisata (Kementerian Pariwisata Republik Indonesia, 2016).

Berdasarkan Permen tersebut terdapat sembilan kriteria dalam standar pemanfaatan ekonomi untuk masyarakat lokal. Kriteria tersebut adalah pemantauan ekonomi, (2) peluang kerja untuk masyarakat lokal, (3) partisipasi masyarakat, (4) opini masyarakat lokal, (5) akses bagi masyarakat lokal, (6) fungsi edukasi sadar wisata, (7) pencegahan eksploitasi, (8) dukungan untuk masyarakat dan (9) mendukung pengusaha lokal dan perdagangan yang adil.

\section{Hasil Penelitian Sebelumnya}

Hasil penelitian sebelumnya dalam ditemukan bahwa dalam pembangunan pariwisata berkelanjutan dibutuhkan partisipasi masyarakat pada seluruh tahapan pembangunan, dimulai dari perencanaan, implementasi pembangunan hingga evaluasi sehingga tumbuh kesadaran masyarakat untuk memelihara hasil dari pembangunan pariwisata. Pengembangan sumber daya manusia pariwisata diperlukan untuk mendukung kesadaran wisata masyarakat yang nantinya akan meningkatkan kesejahteraan masyarakat (Setijawan, 2018).

Andriani dan Sunarta (2015) dalam studinya menyatakan bahwa mengelola potensi alam dan budaya merupakan tantangan dalam pengelaan desa wisata menuju pariwisata berkelanjutan. Dengan keberhasilan dalam pengelolaan tersebut maka akan memberikan manfaat ekonomi bagi masyarakat.

\section{METODOLOGI}

Penelitian ini adalah penelitian kualitatif. Pendekatan kualitatif digunakan untuk mengidentifikasi dan menganalisis pemanfaatan ekonomi untuk masyarakat lokal dalam pembangunan pariwisata berkelanjutan. Lokasi penelitian adalah di Desa Wisata Kereng Bangkirai, Kecamatan Sebangau, Kota Palangka Raya. Jenis data yang digunakan dalam penelitian ini adalah data primer dan data sekunder. Jenis data yang digunakan dalam penelitian ini terdiri dari data primer dan data sekunder. Data primer dalam penelitian ini bersumber dari hasil wawancara secara mendalam dan 
observasi dimana hasil dari data tersebut dikumpulkan dan diolah sendiri oleh penulis. Data sekuder dalam penelitian ini bersumber dari studi pustaka melalui referensi, berbagai jurnal, maupun artikel yang diambil dari internet untuk mendapatkan data yang dibutuhkan dalam penelitian ini. Wawancara dilakukan kepada pengelola desa wisata, komunitas masyarakat, asosiasi, dan industri. Materi wawancara adalah indikator dari sembilan kriteria ruang lingkup pemanfaatan ekonomi untuk masyarakat lokal.

Data yang didapatkan, diolah oleh peneliti sebagai bahan analisis untuk menjawab rumusan masalah yang diajukan. Data yang dianalisis adalah data ordinal 4 poin yaitu 1 adalah kurang, 2 adalah cukup, 3 adalah baik dan 4 adalah istimewa untuk semua indikator. Poin 1 diberikan bila kriteria belum dijalankan dan tidak terdapat bukti pendukung; poin 2 diberikan bila kriteria kurang konsisten dijalankan dan kurang bukti pendukung; poin 3 diberikan bila kriteria sudah dijalankan dan cukup bukti pendukung; dan poin 4 diberikan bila kriteria sudah dijalankan secara konsisten dan bukti pendukung lengkap. Proses analisis data berlangsung sebelum ke lapangan, selama di lapangan dan setelah dari lapangan, sebagaimana yang diungkapkan oleh Sugiyono (2018). Hasil penilaian akan mengidentifikasi manfaat ekonomi untuk masyarakat lokal di Desa Wisata Kereng Bangkirai.

\section{HASIL DAN PEMBAHASAN}

\section{Gambaran Umum Desa Kereng Bangkirai}

Desa atau Kelurahan Kereng Bangkirai berada dalam wilayah Kecamatan Sebangau, Kota Palangka Raya. Akses menuju Kelurahan Kereng Bangkirai dapat melalui jalan darat dengan jarak dari ibu kota provinsi kurang lebih $12 \mathrm{~km}$, dan transportasi sungai dengan menggunakan perahu, kapal motor serta kapal cepat melalui luar Pulau Kalimantan. Penduduk Kelurahan Kereng Bangkirai sebagian besar merupakan Suku Dayak. Kereng Bangkirai sendiri memiliki arti dalam bahasa Dayak Ngaju adalah tanah dataran tinggi yang terdapat pepohonan kayu bangkirai.

Berdasarkan profil kelurahan, terdapat dua daya tarik wisata yang terdapat di desa ini, yaitu Dermaga Kereng Bangkirai dan Pesona Alam Lestari. Pesona Alam Lestari atau yang biasa disingkat PAL merupakan daya tarik wisata yang memiliki banyak fasilitas seperti taman bermain anak-anak, kolam renang, pondok kecil untuk istirahat, serta panggung untuk pertunjukan musik. Sesuai dengan namanya, Pesona Alam Lestari memiliki pemandangan yang indah dengan iklim yang sejuk.

Dermaga Kereng Bangkirai dahulu merupakan lokasi atlet dayung untuk berlatih dan juga tempat penyelenggaraan kejuaraan nasional dayung di Provinsi Kalimantan Tengah. Saat ini Dermaga Kereng Bangkirai memiliki fasilitas wisata seperti pondok wisata yang dapat digunakan oleh wisatawan. Wisatawan yang berkunjung memberikan peluang bagi masyarakat sekitar sekitar untuk membuka usaha penyediaan makan dan minum serta ragam aktivitas wisata yang dapat dipilih oleh para wisatawan seperti aktivitas dengan sepeda bebek air, susur sungai, wisata ke batu ampar, dan lainnya.

\section{Hasil}

Pengumpulan data dari hasil observasi dan wawancara kepada pengelola desa wisata, komunitas masyarakat, asosiasi, dan industri dilakukan pencatatan. Berikut adalah hasilnya: 


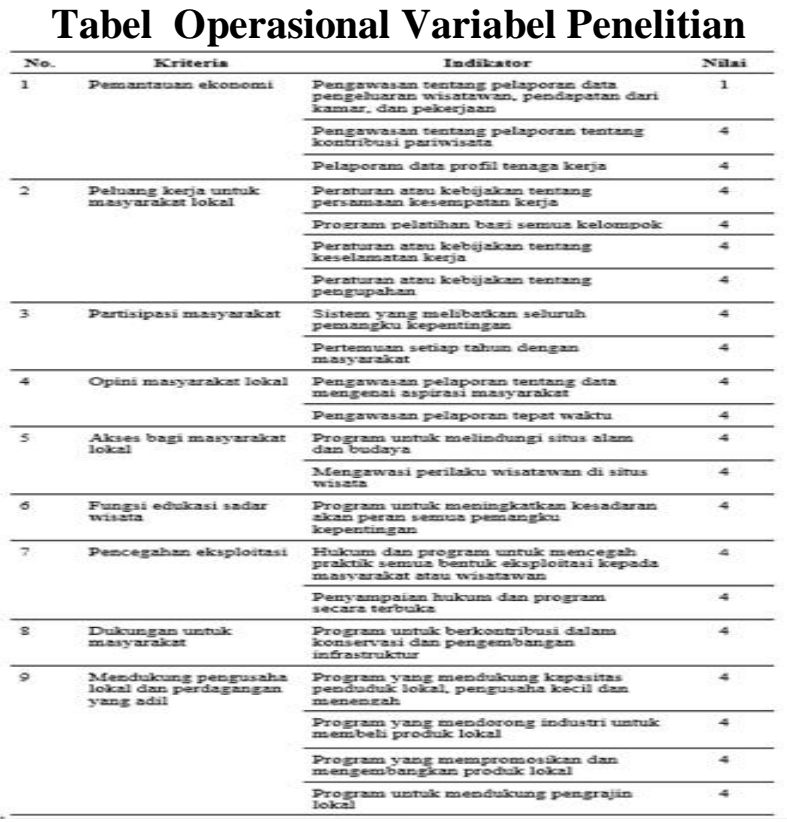

Sumber: Hasil olahan data (2020)

Pada tabel terlihat bahwa hampir di seluruh indikator Desa Wisata Kereng Bangkirang mendapatkan nilai 4 yang artinya adalah istimewa. Hanya 1 indikator yang mendapatkan nilai kurang yaitu pengawasan tentang pelaporan data pengeluaran wisatawan, pendapatan dari kamar, dan pekerjaan.

\section{Pembahasan}

Untuk kriteria pemantauan ekonomi, Pokdarwis Desa Wisata Kereng Bangkirai selaku pengelola memiliki data kunjungan wisatawan, dampak ekonomi, dan profil sumber daya manusia pariwisata. Dalam upaya mewujudkan konsep keberlanjutan dari ekonomi, sosial dan lingkungan, maka prinsip daya dukung harus diperhatikan dengan mengelola kunjungan wisatawan sesuai dengan kapasitas yang mempertimbangkan aspek alam maupun sosial budaya (Kristiana \& Mulyono, 2016), mengingat Desa Wisata Kereng Bangkirai sebagai pintu masuk menuju Taman
Nasional Sebangau. Pelaporan tentang kontribusi pariwisata dibuat dalam bentuk laporan penjualan karcis tanda masuk di kawasan wisata. Pengumpulan dan laporan data profil tenaga kerja dilakukan setiap tahun dan dilaporkan oleh Pokdarwis. Wisatawan yang berkunjung ke Desa Wisata Kereng Bangkirai pada umumnya tidak menginap sehingga Pokdarwis Desa Wisata Kereng Bangkirai tidak memiliki data terkait pendapatan per kamar yang tersedia. Selain itu pengelola tidak memiliki data terkait pengeluaran pengunjung dan investasi, sehingga dinas terkait perlu melakukan pembinaan kepada pengelola dalam melakukan dokumentasi data, monitoring dan pelaporan.

Bukti pendukung kriteria peluang kerja untuk masyarakat lokal yaitu Perda Nomor 1 Tahun 2016 tentang Penyelenggaraan Pendidikan Informal, dan Perda Nomor 13 Tahun 2012 tentang Izin Usaha Jasa Konstruksi. Selain itu tersedia Balai Pelatihan kerja (BLK) di Disnakertrans Kota Palangka Raya dan para tenaga kerja diakomodir dengan kebijakan UMP dan UMK Palangka Raya. Untuk kriteria partisipasi masyarakat, terdapat agenda pertemuan rutin para pemangku kepentingan antara lain Pemerintah Daerah, pelaku pariwisata, dan masyarakat dalam dalam rangka pembangunan dan pemberdayaan masyarakat.

Kriteria opini masyarakat lokal didukung dengan ketersediaan pada Survei Kepuasan Konsumen (SKM) yang dilaksanakan oleh Disbudpar Kota Palangka Raya di Desa Wisata Kereng Bangkirai serta terdapat kotak saran dan kritik untuk aspirasi masyarakat mengenai pengelolaan destinasi wisata. Pengumpulan, dan pelaporan dilakukan secara tepat waktu oleh Pokdarwis ke Disbudpar Kota Palangka Raya. Sedangkan untuk kriteria akses bagi masyarakat lokal, tersedia pusat informasi 
dan call center yang dikelola oleh masyarakat melalui Pokdarwis Kereng Bangkirai dan secara rutin serta berkelanjutan memantau dan menjaga kawasan wisata.

Dalam mendukung kriteria fungsi edukasi sadar wisata, terdapat program sosialisasi dan aksi Sapta Pesona oleh Dinas Kebudayaan dan Pariwisata Kota Palangka Raya, Dinas Kebudayaan dan Pariwisata Provinsi Kalimantan Tengah, Balai Taman Nasional Sebangau dan dinas teknis lainnya. Sapata Pesona dinilai sebagai semboyan pariwisata yang penting untuk diterapkan dalam pengelolaan daya tarik wisata (Tondang, 2018). Untuk pencegahan eksploitasi, terdapat Komisi Penanggulangan AIDS Kota Palangka Raya yang telah melaksanakan program untuk mencegah segala macam bentuk eksploitasi, diskriminasi, praktik komersialisasi, dan mengembangkan sistem proteksi serta pencegahan.

Untuk kriteria dukungan untuk masyarakat, terdapat bantuan cat dari BPJS Provinsi Kalimantan Tengah, adanya pelatihan pemanduan oleh Taman Nasional Sebangau, mendapatkan bantuan mesin dan badan perahu untuk pelaku usaha, mendapatkan bantuan program Kotaku, adanya pelatihan oleh pemberdayaan masyarakat Provinsi Kalimantan Tengah, dan bantuan pemadam kebakaran dari CSR BNF. Dukungan bagi masyarakat ini tertuang dalam Perda Nomor 2 Tahun 2016 tentang Tanggung Jawab Sosial dan Lingkungan Perusahaan di Kota Palangka Raya dan tersedinya data di KPA Kota Palangka Raya.

Pemerintah Daerah mendukung pengusaha lokal dan perdagangan yang adil. Hal ini terlihat dengan adanya program pelatihan, pameran dan kegiatan Palangka Raya Expo yang mendukung masyarakat dan pengusaha kecil serta menengah dalam memperkenalkan dan mengembangkan produk lokal yang berkualitas dan berkelanjutan oleh dinas UMKM dan Koperasi Kota Palangka Raya. Selain itu melakukan kerjasama dengan Indomaret dalam memasarkan produk UMKM. Sektor UMKM dinilai mampu berkontribusi terhadap perekonomian masyarakat (Ngatemin, 2019).

Pemanfaatan ekonomi di Desa Wisata Kereng Bangkirai telah sejalan dengan kriteria dari destinasi pariwisata berkelanjutan. Seperti yang dinyatakan oleh World Tourism Organization (2007) bahwa pariwisata berkelanjutan fokus pada pemanfaatan sumber daya sehingga aspek ekonomi, sosial dan budaya dapat tercapai dengan senantiasa melestarikan budaya, dan melakukan konservasi lingkungan. Untuk mendukung dalam pengembangan desa wisata agar selaras dengan prinsip-prinsip pariwisata berkelanjutan maka seperti yang dinyatakan oleh Hamzah dan Irfan (2018) perlu dibuat pedoman yang dapat menjadi acuan bagi seluruh pemangku kepentingan di Desa Wisata Kereng Bangkirai.

Berdasarkan penilaian dan bukti-bukti pendukung maka dapat disimpulkan bahwa pengembangan pariwisata di Desa Wisata Kereng Bangkirai mampu memberikan manfaat ekonomi bagi masyarakat.

\section{PENUTUP}

\section{Simpulan}

Kereng Bangkirai merupakan desa wisata yang menjadi pintu masuk menuju kawasan Taman Nasional Sebangau. Kereng Bangkirai sebagai daya tarik wisata yang mengembangkan kegiatan untuk membangun kesadaran masyarakat dalam pelestarian lingkungan yang pada akhirnya mampu memberi manfaat ekonomi bagi masyarakat. Desa Wisata Kereng Bangkirai sebagai daya tarik yang berada dalam tahap 
pembangunan akan terus melakukan peningkatan kualitas, dan daya saing produk wisata untuk menarik minat dari wisatawan. Berdasarkan penilaian dan bukti-bukti pendukung maka dapat disimpulkan bahwa pengembangan pariwisata di Desa Wisata Kereng Bangkirai mampu memberikan manfaat ekonomi bagi masyarakat.

\section{Saran}

Untuk memenuhi kriteria dari standar pemanfataan ekonomi di Desa Wisata Kereng Bangkirai agar menjadi destinasi pariwisata yang berkelanjutan, upaya yang perlu dilakukan antara lain: (1) mengadakan pembinaan kepada masyarakat secara berkelanjutan untuk peduli terhadap pelestarian lingkungan sehingga mampu memberi manfaat ekonomi bagi masyarakat; (2) meningkatkan dukungan lintas sektoral dalam pengembangan program pemberdayaan masyarakat yang bukan hanya memberikan manfaat secara ekonomi namun juga dalam tata kelola, pelestarian budaya serta pelestarian lingkungan; dan (3) melakukan pendampingan secara berkelanjutan baik oleh Pemerintah maupun akademisi dalam pencapaian program sehingga nantinya masyarakat dapat secara mandiri menjadi destinasi pariwisata yang berkelanjutan.

\section{UCAPAN TERIMA KASIH}

Ucapan terima kasih ditujukkan kepada Universitas Pelita Harapan karena telah mendanai penelitian ini. Ucapan terima kasih juga diberikan kepada Dinas Kebudayaan dan Pariwisata Kota Palangka Raya, Balai Taman Nasional Sebangau, Pokdarwis dan masyarakat Kereng Bangkirai yang telah mendukung penelitian ini.

\section{DAFTAR PUSTAKA}

Andriani, D., \& Sunarta, I. (2015). Pengelolaan Desa Wisata Belimbing menuju pariwisata berkelanjutan Kecamatan Pupuan, Kabupaten Tabanan, Bali. Jurnal Destinasi Pariwisata, 3(1), 17-23.

Dwyer, L., Forsyth, P., \& Dwyer, W. (2010). Tourism economics and policy. In Tourism Economics and Policy. https://doi.org/10.15291/lib.993

Hamzah, A. S., \& Irfan, M. (2018). Law enforcement of Constitutional Court Decision No. 69/PUU -XII/2015 (mixed marriage issue without marriage agreement). Jurnal Notariil, 3(1), $1-12$. https://doi.org/https://doi.org/10.22225 /jn.v3i1.597

Hariman, H. (2021). Dampak Ekonomi dalam Pengelolaan Homestay di Desa Terong Kabupaten Belitung. Jurnal Akademi Pariwisata Medan. https://doi.org/10.36983/japm.v9i1.74

Inskeep, E. (1991). Tourism planning: An integrated and sustainable development approach. New York: Van Nostrand Reinhold.

Kartika, T. (2017). Dampak pengembangan pariwisata terhadap aspek ekonomi, sosial budaya dan lingkungan fisik di Desa Panjalu. Jurnal Hospitaliti Dan Pariwisata, 3(1). Retrieved from http://jurnal.polimdo.ac.id/index.php/p ariwisata/article/view/96

Kementerian Pariwisata Republik Indonesia. Peraturan Menteri Pariwisata Nomor 14 Tahun 2016 tentang Pedoman Destinasi Pariwisata Berkelanjutan. , (2016).

Kementerian Pariwisata Republik 
Indonesia. (2019). Pengembangan wisata perdesaaan \& wisata perkotaan. Retrieved January 4, 2021, from https://www.kemenparekraf.go.id/asset _admin/assets/uploads/media/pdf/medi a_1593565793_Buku_Pengembangan_ Wisata_Perdesaan_dan_Wisata_Perkot aan.pdf

Kristiana, Y., \& Mulyono, S. T. (2016). Strategi Upaya Pengembangan Pariwisata Berkelanjutan Agrowisata Berbasis Masyarakat Kampung Domba Terpadu Juhut, Provinsi Banten. Jurnal Ilmiah Widya, 3(3), 17. Retrieved from https://ejournal.jurwidyakop3.com/index.php/j urnal-ilmiah/issue/view/12

Metzel, D. (2007). Regional economic effects of large leisure facilities: A methodological and content analysis. Heidelberg University.

Ngatemin, N. (2019). Implementasi akuntansi keuangan Usaha Mikro Kecil dan Menengah (UMKM) pada usaha akomodasi homestay Di Kabupaten Karo. Jurnal Akademi Pariwisata Medan, 7(2), 47-61. https://doi.org/10.36983/japm.v7i2.50

Setijawan, A. (2018). Pembangunan Pariwisata Berkelanjutan dalam Perspektif Sosial Ekonomi. Jurnal Planoearth, 3(1), 7-11. https://doi.org/10.31764/jpe.v3i1.213

Sugiyono. (2018). Metode penelitian kuantitatif, kualitatif dan $R \& D$. Bandung: Alfabeta.

Tondang, B. (2018). Peran promosi dan pengembangan objek wisata Air Terjun Sipiso Piso dalam meningkatkan jumlah wisatawan di Kecamatan Merek Kabupaten Karo. Jurnal Akademi Pariwisata Medan, 6(2), 21-36. https://doi.org/https://doi.org/10.36983 /japm.v6i2
Woltering, M. (2012). Tourism and regional development in German National Parks: Regional economic impact analysis of tourism as main part of a socioeconomic monitoring system. University of Würzburg.

World Tourism Organization. (2007). A practical guide to tourism destination management.

https://doi.org/10.18111/97892844124 33

\section{UCAPAN TERIMA KASIH}

Penulis mengucapkan terima kasih kepada Direktur Politeknik Pariwisata Medan atas bantuan dan dukungannya sehingga publikasi hasil penelitian ini dapat diterbitkan. 